Viso - Cadernos de estética aplicada Revista eletrônica de estética

ISSN 1981-4062

No 13, jan-jun/2013

http://www.revistaviso.com.br/

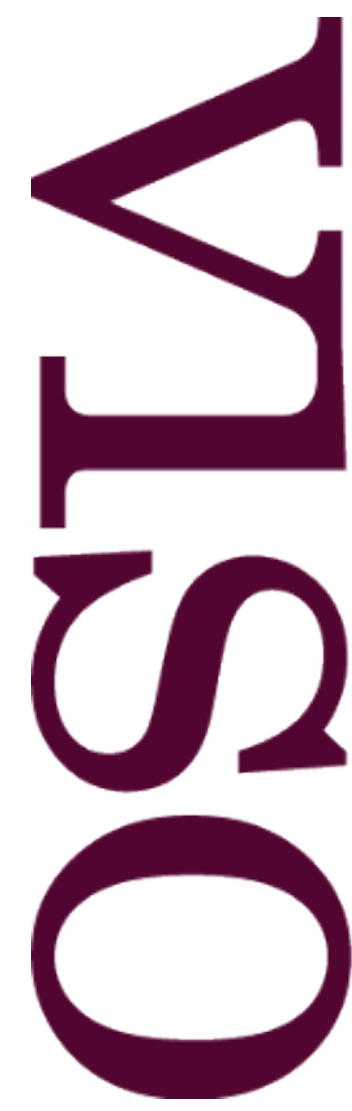

\title{
Blade Runner, pós-modernidade e totalitarismo Aldo Dinucci
}




\section{RESUMO}

\section{Blade Runner, pós-modernidade e totalitarismo}

Em 2012 tivemos o trigésimo aniversário tanto do lançamento do filme Blade Runner, do diretor Ridley Scott, quanto da morte do escritor de ficção científica Philip K. Dick, cujo livro intitulado Do Androids Dream of Electric Sheep? (Sonham os Androides com carneiros elétricos?) inspirou a película. Nas páginas seguintes, analisarei alguns aspectos do filme Blade Runner, mostrando que se pode ver nele uma metáfora da pósmodernidade e do totalitarismo que acompanha esta última.

Palavras-chave: Blade Runner - Philip K.Dick - pós-modernidade

\section{ABSTRACT}

\section{Blade Runner, Postmodernity and Totalitarianism}

In 2012 we had both the thirtieth anniversary of the release of the film Blade Runner, of the director Ridley Scott, as the death of the science fiction writer Philip K. Dick (who now call simply PKD), whose book Do Androids Dream of Electric Sheep? inspired the film. In the following pages, I will analyze some aspects of the film Blade Runner, showing that one can see in it a metaphor of post-modernity and the totalitarianism that follows the latter.

Keywords: Blade Runner - Philip K.Dick - postmodernity 
DINUCCI, A. "Blade Runner, pós-modernidade e totalitarismo". In: Viso: Cadernos de estética aplicada, v. VII, n. 13 (jan-jun/2013), pp. 9-21.

DOI: 10.22409/1981-4062/v13i/148

Aprovado: 01.07.2013. Publicado: 29.10.2013.

(C) 2013 Aldo Dinucci. Esse documento é distribuído nos termos da licença Creative Commons Atribuição-NãoComercial 4.0 Internacional (CC-BY-NC), que permite, exceto para fins comerciais, copiar e redistribuir o material em qualquer formato ou meio, bem como remixá-lo, transformá-lo ou criar a partir dele, desde que seja dado o devido crédito e indicada a licença sob a qual ele foi originalmente publicado.

Licença: http://creativecommons.org/licenses/by-nc/4.0/deed.pt_BR

Accepted: 01.07.2013. Published: 29.10.2013.

(C) 2013 Aldo DInucci. This document is distributed under the terms of a Creative Commons Attribution-NonCommercial 4.0 International license (CC-BY-NC) which allows, except for commercial purposes, to copy and redistribute the material in any medium or format and to remix, transform, and build upon the material, provided the original work is properly cited and states its license.

License: http://creativecommons.org/licenses/by-nc/4.0/ 
Em 2012 tivemos o trigésimo aniversário tanto do lançamento do filme Blade Runner, do diretor Ridley Scott ${ }^{1}$, quanto da morte do escritor de ficção científica Philip K. Dick (que doravante chamarei simplesmente de PKD), cujo livro intitulado Do Androids Dream of Electric Sheep? (Sonham os Androides com carneiros elétricos?) $)^{2}$ serviu de base à película. Nas páginas seguintes, analisarei alguns aspectos do filme Blade Runner, mostrando que se pode ver nele uma metáfora da pós-modernidade e do totalitarismo que acompanha esta última.

Antes de tudo, é preciso dizer que $\mathrm{PKD}^{3}$ é universalmente considerado um dos mais importantes escritores de ficção científica de todos os tempos, sobretudo pelo caráter filosófico e questionador de seus romances e contos. Ao invés de se fixar em imaginar sofisticados mundos tecnológicos futuros com personagens unidimensionais, projetando para o amanhã os conflitos políticos de sua época, PKD procurou, em seus escritos, avaliar o impacto do desenvolvimento tecnológico sobre os indivíduos e seus sistemas de valores. Assim, os romances de PKD exploram mundos nos quais sistemas de valores bizarros criam sistemas autoritários contra os quais indivíduos racionalmente críticos ou simplesmente revoltados se indispõem. ${ }^{4}$

PKD percebeu que um mundo tecnologicamente avançado não significa necessariamente um mundo de valores ordenados científica ou racionalmente. Profetizando ou antecipando nossos dias, PKD imaginou sociedades ao mesmo tempo altamente desenvolvidas tecnologicamente e governadas por valores desumanizantes e totalitários. O filme Blade Runner conseguiu sintetizar tais concepções de PKD a ponto de ser visto hoje como exemplificando o debate acerca da pós-modernidade. ${ }^{5}$

Refletindo sobre o mundo atual e o impacto do desenvolvimento tecnológico e científico sobre nosso sistema de valores, o filósofo alemão Sloterdijk, em sua famosa conferência intitulada "Regras para o Parque Humano, uma resposta à carta de Heidegger sobre o humanismo"6, atentou para o fato de que nossa sociedade não mais partilha os ideais humanistas que vigoraram no Ocidente a partir de certa época após o advento da escrita. Para Sloterdijk, tal advento, combinado, na Grécia, com a invenção da filosofia, criou em torno de si uma comunidade de amigos à distância no tempo e no espaço. Por exemplo: em torno dos escritos de Epicuro instituiu-se uma comunidade de filósofos (os epicuristas) que se dedicou a praticar as concepções e os valores epicuristas, preservar tais obras e difundi-las na medida do possível. E o mesmo se deu em torno de muitos filósofos, como Sócrates, Platão, Aristóteles, Zenão de Cítio. Assim, a difusão e a preservação da cultura humanista se fundavam essencialmente na preservação e transmissão da palavra escrita através de uma comunidade baseada na amizade.

Entretanto, observa Sloterdijk, a Segunda Guerra pôs em xeque tais valores humanistas, pois muitos viram nela o fracasso das aspirações e promessas do lluminismo e da ciência quanto a um mundo mais justo, fundado em valores racionais. Nas bombas atômicas jogadas sobre o Japão ou nas fábricas nazistas da morte que mataram 
milhões, vemos a ciência empregada para fulminar seres humanos, utilidade para a qual ela não foi concebida inicialmente, mas para o que acabou incidentalmente servindo. Além disso, os meios pós-modernos de comunicação (rádio, televisão, telefone, internet) contribuíram para colocar em segundo plano a escrita como meio de difusão cultural. A partir dessas constatações, Sloterdijk conclui que, por essas duas razões principais, a concepção humanista viu-se por terra, desempenhando agora um papel menor e sendo substituída por uma concepção de controle social que busca adestrar os homens, seja pelos meios pós-modernos de comunicação, seja por uma intervenção científica que visa em última análise ao controle genético do ser humano.

Todos os mundos alternativos dos romances e contos de PKD, sempre invariavelmente distopias, seguem num grau ou noutro essa concepção de Sloterdijk quanto à combinação de tecnologia e valores desumanizantes e totalitários. Em Blade Runner, o cenário que se apresenta é o de um mundo pós-guerra atômica, extremamente desenvolvido tecnologicamente. Os valores de tal mundo, entretanto, são aqueles que comumente identificamos como os do capitalismo tardio, caracterizado pela intensificação dos fluxos internacionais do capital, pela globalização, pela expansão das grandes corporações multinacionais e pelo consumo de massa, levando finalmente à exaustão dos recursos naturais. ${ }^{7}$ No filme em questão, Rick Deckard, o personagem que é encarregado de eliminar androides extraviados na Terra, vai à Tyrell Corporation, a corporação poderosíssima que produz tais androides, para interrogar uma androide que ignora sua condição e crê ser um "ser humano genuíno". Deckard fica estupefato ao constatar tal fato, e o presidente da corporação explica-lhe que se trata de uma experiência com implantes de memória, deixando claro que o objetivo da Tyrell é simplesmente gerar lucro, e que nada mais é levado em consideração senão isso. ${ }^{8}$ Essa asserção de Tyrell reflete o mundo tecnologicamente avançado no qual o drama ocorre: tal mundo não é aquele da vitória do humanismo, da ciência e da razão, não é um mundo sonhado por um lluminista. Como observa Giuliana Bruno ${ }^{9}$, o filme se passa não em uma estação espacial ou espaçonave, mas em uma futura Los Angeles pósindustrial, na qual

o futuro não realiza [..] uma ordem tecnológica asséptica e idealizada [...] A cidade de Blade Runner não é uma cidade ultramoderna, mas pós-moderna [...] ela cria uma estética da decadência, expondo o lado obscuro da tecnologia, o processo de desintegração.

O caráter decadente da sociedade imaginada em Blade Runner é explicitado por um oficial da polícia (Bryant) que, ao convocar Deckard para voltar ao serviço de eliminar androides, observa que, se Deckard não aceitasse a incumbência, seria considerado "little people", isto é: "gentinha".$^{10}$ Parafraseando a mensagem do oficial: "Nesse mundo ou você é um de nós, guardiães da ordem constituída, ou é escória, tendo direitos e salvaguardas apenas no primeiro caso". Assim, numa sociedade desumanizada, onde não imperam efetivamente os valores de igualdade entre os homens, prevalece pura e simplesmente o direito do mais forte. $E$ tal sociedade se mantém pela força, pelo terror e 
pela eliminação daqueles que não compartilham seus valores ou mesmo certas características psicológicas e físicas, e tudo isso ocorrendo de forma explícita, pois, sem a oposição dos valores humanistas, não mais se vê necessária qualquer dissimulação quanto a isso.

Assim, a película não somente reflete sobre o capitalismo tardio, mas também sobre algo que parece necessariamente acompanhá-lo: a pós-modernidade. Como sustenta Kagan em $O$ retorno da história ${ }^{11}$, em consonância com as teses de Sloterdijk no texto supracitado, é pós-moderna uma sociedade na qual os valores modernos e clássicos do humanismo (tais como a afirmação da igualdade entre os homens baseada numa visão racional do universo) já não mais vigoram ou são letra morta. Digo "já não mais" porque só pode ser pós-moderna uma sociedade que já foi moderna. Entretanto, embora sem mais acalentar os valores modernos, humanistas e, porque não dizer, clássicos (pois tais valores foram cultivados por certas vertentes filosóficas desde a Grécia clássica), a ciência, que nasceu sob o signo humanista, persevera, já não mais como meio de se conhecer a harmonia da natureza e suas leis, mas meramente como instrumento para o controle, a opressão e a acumulação de capital.

Vemos desenhar-se diante de nossos olhos uma situação paradoxal: é pós-moderna uma sociedade que possui uma ciência e uma tecnologia avançadas, como nem os mais entusiastas cientistas da Antiguidade e da Modernidade poderiam imaginar, mas que é governada por valores autoritários, anticientíficos e desumanizantes. Chamo de valor desumanizante aquele que não supõe uma noção viva de igualdade entre os homens baseada numa visão naturalista do mundo. E são esses valores que imperam em Blade Runner e que querem se impor na sociedade atual, causando diretamente guerras e conflitos de toda ordem sob o estandarte das falanges radicais das religiões monoteístas que, agora libertas dos freios morais do humanismo, voltam ao seu modo pré-moderno de conduta. Exemplo disso é que, mesmo em países ditos democráticos e liberais, vemos a tentativa de grupos ultraconversadores de colocar em pauta e fazer vigorar como normais e leis seus valores pré-modernos no que tange à sexualidade e mesmo à ciência.

Quanto a isso, Robert Kagan ${ }^{12}$, em O retorno da história, considera o tema da reconfiguração geopolítica das forças no mundo contemporâneo. Kagan identifica o fim da Guerra Fria como ponto crucial dessa reconfiguração. Com a morte do comunismo soviético, o Ocidente dito democrático achou que morriam junto todos os conflitos ideológicos e estratégicos da humanidade e se sacramentava o sonho moderno de uma economia globalizada e liberal. O capitalismo dito democrático, como anunciara Fukuyama em The End of History and the Last Man, parecia ser a única opção plausível no novo mundo pós-URSS. Essas expectativas, reflete Kagan ${ }^{13}$, deviam-se à convicção iluminista de que a história se move apenas em uma direção, convicção esta que, posta temporariamente de lado pela carnificina do século XX, voltou a imperar com o colapso do comunismo soviético. 
Após a guerra fria, as "democracias" capitalistas, capitaneadas pelos EUA e sob o signo da crença iluminista de que o comércio seria capaz de moldar o homem e extirpar-lhe a ferocidade, incumbiram-se da tarefa de criar um sistema internacional de leis que propiciassem a emergência de um mundo dito democrático, liberal e sem guerras, mundo no qual a geoeconomia tomaria o lugar da geopolítica.

Entretanto, em meio a tal otimismo, vários sinais de oposição foram ignorados. Uma parte significativa do mundo, por motivos religiosos e nacionalistas, mantinha-se à margem desse anseio ocidental pelo liberalismo econômico, político e moral.

De fato, ao longo dos anos de 1990, uma profunda transformação começou a ocorrer no mundo. A China e a Índia começaram a crescer economicamente. A seguir, a própria Rússia se soergueu em meio à calamidade em que se encontrava e começou a dar mostras de recuperação econômica. Tal recuperação, porém, deu-se em meio a um retrocesso quanto ao liberalismo, tanto em questões internas quanto internacionais. A Rússia de Putin, a despeito das previsões geoeconômicas liberais, tornou-se nacionalista e autocrática. A ascensão da Rússia nos moldes atuais, reflete Kagan ${ }^{14}$, parece indicar que, ao contrario do que criam os modernos, a conquista de riqueza pelas nações não produz necessariamente uma harmonia mundial, mas antes incita uma maior competição entre elas.

Some-se a isso o inopinado crescimento da China. Esperava-se também que a China, com seu desenvolvimento econômico que a coloca como forte candidata à liderança mundial, se inclinasse para o liberalismo político. Entretanto, o crescimento econômico da China é acompanhado por um grande investimento em suas forças armadas (a China é o segundo país que mais investe em armamentos no mundo), além de despertar um forte nacionalismo e de fortalecer a autocracia que a vem governando por décadas.

Vai-se constituindo um cenário no qual a progressão do capitalismo internacional não é acompanhada pela universalização do liberalismo político e da democracia (como sonhavam os modernos), mas antes por uma reconfiguração do equilíbrio geopolítico de forças que passa a operar não mais a partir da antinomia democracia-comunismo, mas a partir do embate ideológico entre democracias e autocracias.

Tal situação se repete e se aprofunda no mundo islâmico. Tradicionalmente resistente a mudanças e reformas políticas e morais, vários países islâmicos combinam, como a China, um crescente desenvolvimento e enriquecimento econômico com um progressivo enrijecimento político e moral. E no mundo islâmico as autocracias tornam-se teocracias. Exemplo disso é o Irã, que, antes um aliado dos EUA, passou por uma reviravolta interna há algumas décadas, transformando-se numa teocracia com aspirações nucleares em busca da hegemonia regional, o que, como se sabe, vem gerando grande preocupação no Ocidente dito democrático. 
Os Estados Unidos, por outro lado, com o fim da guerra fria, não reduziram seu empenho quanto à manutenção e ampliação do seu controle mundial. Pelo contrário, como observa Kagan ${ }^{15}$, entre 1989 e 2001 os Estados Unidos intervieram militarmente em países estrangeiros mais que em qualquer outro momento de sua história, e muito mais que qualquer outro país no mesmo período.

Kagan defende a tese de que, ao invés de termos chegado ao fim da história com o fim do comunismo e a difusão do capitalismo internacional, atingimos outra configuração política mundial na qual uma crescente riqueza das nações leva não à paz, mas antes ao conflito entre o eixo das democracias e o eixo das autocracias, estas últimas fortalecidas justamente pelo enriquecimento que atingiram através do desenvolvimento do capitalismo internacional.

A partir disso, visualizamos nossa época como aquela na qual o sonho moderno de um mundo no qual a internacionalização do comércio levaria ao liberalismo moral e político e à paz perpétua entre as nações é decididamente posto em xeque - isso se já não tiver sido refutado.

Acima me referi ao Ocidente dito democrático para fazer ver que, ao entrar em conflito com as autocracias, as democracias se colocam no mesmo plano, igualando-se a elas no desrespeito aos valores democráticos básicos. Diversas incursões recentes do Ocidente no Oriente islâmico são exemplos disso. Em nome da "democracia" tudo se justifica: bombardeios a populações civis, a eliminação de um cidadão americano islâmico sem julgamento (Anwar al Aulaqi), a eliminação de Muamar Kadafi, além de vários ataques pontuais com drones que vêm sistematicamente eliminando líderes palestinos. Digo "eliminação" porque esses indivíduos foram mortos a despeito dos princípios que comumente vigoram em sociedades democráticas, quais sejam: "Todo mundo é inocente até que se prove o contrário" e, consequentemente, "Todos têm direito a um julgamento justo". Lembremos que vários líderes nazistas foram julgados e condenados no tribunal de Nuremberg: naquele momento ainda vigoravam valores modernos e liberais, e era inconcebível simplesmente eliminar pessoas em nome da "democracia". ${ }^{16} \mathrm{O}$ direito a julgamento como direito básico numa sociedade realmente democrática é asseverado desde Sócrates. Como sabemos, Sócrates se opôs ao julgamento en masse de dois generais atenienses, após a vitória de Atenas sobre Esparta na batalha de Arginusas. ${ }^{17}$ Assim, na Declaração universal dos direitos humanos, adotada e proclamada pela resolução 217 A (III) da Assembleia Geral das Nações Unidas em 10 de dezembro de 1948, no artigo xxiv, parágrafo 2, lemos que

no exercício de seus direitos e liberdades, toda pessoa estará sujeita apenas às limitações determinadas pela lei, exclusivamente com o fim de assegurar o devido reconhecimento e respeito dos direitos e liberdades de outrem e de satisfazer às justas exigências da moral, da ordem pública e do bem-estar de uma sociedade democrática. 
toda pessoa acusada de um ato delituoso tem o direito de ser presumida inocente até que a sua culpabilidade tenha sido provada de acordo com a lei, em julgamento público no qual lhe tenham sido asseguradas todas as garantias necessárias à sua defesa. ${ }^{18}$

Na era pós-moderna esses valores começam a cair. Nesse contexto podemos pensar os androides no filme. A sociedade de Blade Runner é tão avançada que pode construir peça por peça seres humanos. As peças não são mecânicas ou metálicas, mas de carne e osso, idênticas às dos seres humanos "naturais". Além disso, os androides são superiores aos humanos "naturais" em força e intelecto. Apenas uma limitação é neles introduzida para diminuir seu potencial: têm vida curta. A utilidade de tais androides é o trabalho escravo em colônias extraterrestres de humanos naturais. Entretanto, alguns androides se rebelam em suas colônias e voltam para a terra, tentando desesperadamente um meio para dilatarem seu tempo de vida. Essa é uma característica básica dos personagens centrais de PKD: a revolta contra o status quo. Todos eles vivem em sociedades onde vigoram valores pré-modernos e tecnologia pósmoderna, ou seja: sociedades fechadas e tecnologicamente avançadas. Platão, no livro V da República, teorizou perfeitamente as sociedades fechadas 19: abaixo dos "filósofos", temos os guardiões, encarregados de manter pela força o poder e o ideário da classe dominante. Todos os sistemas totalitários possuem tais "guardiões"' - por exemplo: a Gestapo nazista, a KGB soviética, a ClA norteamericana. A função de tais instituições é controlar o que se pensa e o que se diz numa sociedade fechada, identificar os insatisfeitos e eliminá-los social ou fisicamente. Isso é feito em nome de uma suposta verdade cuja função seria justamente oferecer uma organização ótima para a sociedade. Assim, se tal verdade tem função social, o inimigo da verdade é antissocial. Consequentemente, em nome do bem-estar da sociedade, é preciso eliminar os inimigos da verdade. E vemos justificadas a perseguição e a eliminação de minorias ou indivíduos insatisfeitos como se fosse um ato em prol da sociedade, pois, por serem inimigos da verdade (do capitalismo, da "democracia"), não merecem julgamento e sua eliminação é boa e desejável por si mesma, além de meritória.

Ora, a pretensão de possuir a verdade é justamente aquela atacada por Sócrates, quando diz, na Apologia, não caber, por seu caráter imperfeito, a nenhum ser humano a posse da verdadeira sabedoria, mas somente aos Deuses. ${ }^{20}$ Essencialmente democrático, esse princípio, se realmente aplicado, dilui todas as tensões de supremacia étnica, religiosa e política, relativizando todo o conhecimento de caráter humano, fundamentando também a concepção científica (pois na ciência também não há teoria absolutamente verdadeira). Ao dissipar a ilusão da posse da verdade, tal princípio derruba as muralhas das supostas hegemonias da verdade e aponta para a igualdade e a comunidade de todos os homens, remetendo-nos aos ideais cosmopolitas, tão caros aos modernos, que, após a queda do muro de Berlim e durante parte da década 1990, eram designados pela expressão, hoje superada pela pós-modernidade, "aldeia global". 
Voltando ao filme, podemos dizer que o protagonista Rick Deckard é como um guardião: sua missão, já dissemos, é eliminar os androides transviados na Terra. ${ }^{21} \mathrm{O}$ androide, marginal e desprovido de direitos, é o outro, o inimigo da verdade. A verdade do sistema é a acumulação de capital e a manutenção de si mesmo, e o androide tem suas próprias e legítimas aspirações "existenciais": quer estender sua vida, quer viver plenamente. O androide, como um filósofo clássico cínico, tem os olhos voltados totalmente para a sua própria existência e despreza os reis (na verdade o androide Roy em Blade Runner acaba por matar o presidente da Tyrell Corporation). $\mathrm{O}$ androide não é mais manipulável após sua revolta, não é mais "útil”. Não reconhecendo seu caráter manufaturado, lançase à vida e, nesse movimento, refuta objetiva e existencialmente a sociedade pósmoderna e seus titereiros. Também a androide Rachel, que Deckard conhece e interroga na Tyrell Corporation, ao tomar ciência de sua condição, revolta-se, foge e acaba se envolvendo amorosamente com ele. Ela também refuta objetiva e existencialmente o sistema: lançar-se ao amor é lançar-se à vida, e o sistema não a produziu para isso. Ela foi produzida para ser um artefato - e, na sociedade pós-moderna, cada vez mais o ser humano, domesticado como os frangos numa granja industrial, é um artefato - mas se revolta contra a sua condição. Finalmente, Rick Deckard também se revolta, junto com Rachel, e escapa também. Na verdade é, por certo ângulo, simples refutar um sistema opressivo, como PKD demonstra muito bem com seus protagonistas revoltados: basta deixar de crer no sistema autoritário. E é isso que é mais temido por tais sistemas. Daí a necessidade de assegurar-se diariamente da submissão das massas pelos meios de controle de crença e de desacreditar todo aquele que, ao pôr em xeque o sistema de valores da sociedade na qual vive e recusar o papel que the é socialmente imposto, refuta com sua própria vida a sociedade fechada e segue em outra direção.

Observe-se que não se trata de defender seja Osama Bin Laden seja algum outro suposto terrorista, mas enfatizar que as democracias, ao eliminarem sem julgamento seres humanos, acabam por se autorrefutar, na medida em que, assim agindo, igualamse, ou antes rebaixam-se, aos sistemas autocráticos que buscam superar.

Mas há outro elemento pós-moderno no filme e na sociedade atual que iguala supostas democracias e autocracias, revelando-as como tão somente máscaras para um onipresente e onipotente capitalismo tardio. Trata-se das periferias das grandes cidades atuais, tão bem representadas no filme em questão. Um elemento básico de uma cidade pós-moderna é o pastiche: a sobreposição de elementos arquitetônicos de diferentes épocas numa mesma paisagem..$^{22}$ Nos sets de filmagem de Blade Runner foram aproveitados diversos cenários de filmes anteriores, conferindo ao filme um aspecto pósmoderno quanto ao pastiche e, ao mesmo tempo, a visão de um futuro (presente) decadente quanto às periferias deterioradas e repletas de destroços das megalópoles. Tal "futuro" já é presente e facilmente constatável. Como observa Mike Davis, em seu célebre Planet of Slums ${ }^{23}$, a desindustrialização, causada pelas mudanças no eixo mundial de poder, bem como o êxodo rural, causado pelas políticas econômicas do FMI e do Banco Mundial, têm produzido um estranho fenômeno: o crescimento das cidades 
desacompanhado do crescimento econômico, produzindo periferias favelizadas e favelizando regiões antes ricas. ${ }^{24} \mathrm{O}$ panorama que Davis projeta para o futuro próximo é o de um mundo de favelas:

As cidades do futuro, ao invés de serem feitas de vidro e aço, como vistas pelas gerações anteriores de urbanistas, são, ao invés disso, construídas de tijolos nus, palha, plástico reciclado, blocos de cimento e restos de madeira. Ao invés de cidades de luz elevando-se aos céus, muito do mundo urbano do século vinte e um irá se agachar em miséria, cercada de poluição, excremento e degradação. ${ }^{25}$

Da mesma forma, apesar de altamente tecnológico, o mundo de Blade Runner é regido por valores consistentes com os do capitalismo tardio, no qual o consumismo gera lixo, escombros, ruínas, e esse lixo, esses escombros e essas ruínas acabam pouco a pouco perfazendo a paisagem. E os próprios seres humanos, desumanizando-se, vão também paulatinamente sendo absorvidos por esses detritos, encontrando-se com eles na cidade decadente, nas favelas, nas periferias miseráveis, nas quais as coisas consideradas sem qualquer valor são descartadas juntamente com seres humanos considerados também como desprovidos de valor e de direitos. No filme, esse caráter decadente é evidente: por exemplo, a cena em que Deckard recebe uma ligação em seu carro, parando por instantes numa região periférica, e seu carro começa imediatamente a ser atacado e saqueado por mutantes marginais.

Assim é o cenário urbano periférico da pós-moderna Los Angeles em Blade Runner: uma espécie de anticidade mergulhada nas trevas, na poluição, em ruínas. Um ambiente decadente, morada de seres humanos descartados culturalmente e sem esperança. Estes, ao contrário dos androides em Blade Runner, ou dos antagonistas das "democracias" do mundo atual, não precisam ser eliminados pelos guardiões. São vistos pelo atual sistema como "little people", escória, e, como não representam perigo imediato para a "civilização", são abandonados à própria sorte, sem educação, saúde e direitos civis reais.

Em determinada cena do filme, na qual o guardião Deckard se aproxima do androide Roy Batty para eliminá-lo, vê-se, no céu noturno, um dirigível anunciando: "Uma nova vida espera por você nas colônias fora do mundo. A chance de começar de novo numa terra dourada de oportunidade e aventura". ${ }^{26}$ Isto é: na anticidade vive-se uma antivida. Todos são perdedores. Não vivem verdadeiramente, mas simplesmente vegetam. Da mesma forma, o ser humano, na sociedade pós-moderna, se não se encaixar em certos parâmetros e não se adequar à ideologia dominante, é visto como desprovido de valor, torna-se absolutamente inútil e indesejável - e é descartado no "lixo" das periferias. 
* Aldo Dinucci é professor associado do Departamento de Filosofia da UFS.

${ }^{1}$ SCOTT, R. Blade Runner. Warner Brothers, 1982.

${ }^{2}$ DICK, P. K. Do androids dream of electric sheep? New York: Doubleday and Company, 1968.

${ }^{3}$ Philip Kindred Dick viveu entre 16 de dezembro de 1928 e 2 de março de 1982. Vencedor do prêmio Hugo de ficção científica em 1963, publicou 44 romances e aproximadamente 121 contos.

${ }^{4}$ Jean Baudrillard ("Two essays: 1.simulacra and science fiction”. In: Science Fiction Studies, n. 55, v. 18, p. 3, 1991) nos diz que PKD não cria um cosmos alternativo, pois "o leitor está, desde o início, numa simulação total sem origem, passado ou futuro. Não é uma questão de universos paralelos [...] ou mesmo possíveis. É hiperreal. É um universo de simulação". Isso porque, para Baudrillard, em PDK pela primeira vez temos o fim da duplicidade que caracterizava a ficção científica: os mundos de PKD não são outros mundos em relação ao nosso, mas mundos sem exterioridade, nos quais os leitores são atirados "sem espelhos ou projeção ou utopias como meios de reflexão".

${ }^{5}$ Cf. CSICSERY-RONAY, I. "Marxist theory and science fiction". In: The Cambridge Companion to Science Fiction. JAMES, E.; MENDLESOHN, F. (orgs.) Cambridge: Cambridge University, 2003, p. 122.

${ }^{6}$ SLOTERDIJK, P. [1999] Regras para o Parque Humano. Uma resposta à carta de Heidegger sobre o humanismo. Tradução de José Oscar de A. Marques. São Paulo: Estação Liberdade, 2000.

${ }^{7}$ Cf. MANDEL, E. O capitalismo tardio. São Paulo: Abril Cultural, 1982.

${ }^{8} \mathrm{O}$ dialogo é o seguinte:

Deckard: She doesn't know?!

Tyrell: She's beginning to suspect, I think.

Deckard: Suspect? How can it not know what it is?

Tyrell: Commerce is our goal here at Tyrell. More human than human is our motto. Rachel is an experiment, nothing more. We began to recognize in them a strange obsession. After all they are emotionally inexperienced with only a few years in which to store up the experiences which you and I take for granted. If we gift them the past we create a cushion or pillow for their emotions and consequently we can control them better.

Deckard: Memories. You're talking about memories.

Cf. o script de Blade Runner disponível em <http://www.trussel.com/bladerun.htm>. Acesso em 19/10/2013.

${ }^{9}$ BRUNO, G. "Ramble City: Postmodernism and Blade Runner". In: October, n. 41, 1987, p. 63.

${ }^{10} \mathrm{O}$ diálogo entre ambos é o seguinte:

Bryant: Stop right where you are. You know the score pal. If you're not cop, you're little people.

Deckard: No choice, huh?

Bryant: No choice pal.

Cf. o script de Blade Runner. Op. cit.

${ }^{11}$ KAGAN, R. O retorno da história. Tradução de Felipe Antunes de Oliveira. Rio de Janeiro: Rocco, 2008.

12 Ibidem, p. 6.

${ }^{13}$ Ibidem, p. 10. 
14 Ibidem, p. 28.

15 Ibidem, p. 53.

${ }^{16}$ Cf. FONTETTE, F. de. Le Proces de Nuremberg. Paris: PUF, 1996.

${ }^{17}$ Cf. XENOFONTE. Helléniques. Livres1-3. Tradução de J. Hatzfeld. Paris: Les Belles Lettres, 1954, 1.7.1-35.

18 Cf. Declaração universal dos direitos humanos. Disponível em <http://portal.mj.gov.br/sedh/ct/legis_intern/ddh_bib_inter_universal.htm>. Acesso em 19/10/2013.

${ }^{19}$ Platão é colocado por Popper entre os inimigos da Sociedade Aberta (Cf. POPPER, K. The open society and its enemies. Londres: Routledge, 1945).

${ }^{20}$ Cf. PLATÃO, Apology. Tradução de Harold North Fowler. Londres: Harvard University, 1995, p. 22 ss. Popper considera que Platão trai Sócrates na República ao representá-lo como simpatizante do totalitarismo. Cf. RYLE, G. "Popper, K.R. - The Open Society and its Enemies". In: Mind, n. 40,1948, pp.167-172.

${ }^{21}$ Como nos diz a legenda com a qual o filme se inicia: Early in the 21st Century, THE TYRELL CORPORATION advanced robot evolution into the NEXUS phase - a being virtually identical to a human - known as a Replicant. The NEXUS 6 Replicants were superior in strength and agility, and at least equal in intelligence, to the genetic engineers who created them. Replicants were used OffWorld as slave labor, in the hazardous exploration and colonization of other planets. After a bloody mutiny by a NEXUS 6 combat team in an Off-World colony, Replicants were declared illegal on earth - under penalty of death. Special police squads - BLADE RUNNER UNITS - had orders to shoot to kill, upon detection, any trespassing Replicant. This was not called execution. It was called retirement. Cf. o script de Blade Runner. Op. cit.

${ }^{22}$ Cf. JAMESON, F. "Postmodernism and Consumer Society". In: FOSTER, H (org.) The AntiAesthetic: Essays on Post-Modern Culture. Seattle: Bay, pp. 111-125.

${ }^{23}$ DAVIS, M. Planet of Slums. Nova lorque: Verno, 2006.

${ }^{24}$ Ibidem, p. 13ss.

${ }^{25}$ Ibidem, p. 19.

${ }^{26}$ A new life awaits you in the Off-World colonies. The chance to begin again in a golden land of opportunity and adventure. New climate, recreational facilities.....absolutely free. Cf. o script de Blade Runner. Op. cit. 